\title{
The Future of Higher Education
}

\section{in the Light of Artificial Intelligence Transformations}

\author{
Dr. Share Aiyed M Aldosari ${ }^{1}$ \\ ${ }^{1}$ Associate Professor - Education College - Prince Sattam Bin Abdulaziz University - Saudi Arabia (November, \\ 2019) \\ Correspondence: Dr. Share Aiyed M Aldosari, Associate Professor - Education College - Prince Sattam Bin \\ Abdulaziz University - Saudi Arabia (November, 2019).
}

Received: January 14, 2020

Accepted: March 13, 2020

Online Published: March 20, 2020

doi:10.5430/ijhe.v9n3p145

URL: https://doi.org/10.5430/ijhe.v9n3p145

\begin{abstract}
This study discussed the potential effects of artificial intelligence on higher education at Prince Sattam Bin Abdulaziz University. To achieve this goal, a qualitative research methodology was used by asking an open question on a sample of academics. The results of the analysis showed that there is a decrease in the level of awareness of the mechanisms of applying artificial intelligence, and that there is a need to further spread awareness in The Saudi environment on the possibilities of using artificial intelligence applications in education
\end{abstract}

Keywords: higher education, artificial intelligence, education's future, educational leadership

\section{Introduction}

Artificial intelligence is one of the most prominent modern applications of information systems as a field of modern knowledge that is interested in studying and understanding the nature of human intelligence and its simulations to create a new generation of smart computers that can be programmed to accomplish many of the tasks that need a high ability of inference, deduction and perception, which are qualities that people enjoy It is included in the list of smart behaviors.

Artificial intelligence applications are important in the fields of life, but they are more important for educational institutions and universities, which represent a great necessity that cannot be dispensed with, as universities today are no longer limited to education, but rather have become an essential part of the system of sustainable development in societies, as it stresses (Morín, 2018) The mission of universities today exceeded the traditional function of preserving heritage, identity and education. Rather, universities today are required to keep pace with technological development through the creation of new methods of education and teaching.

So educational reform projects quickly developed their education systems in accordance with the requirements of artificial intelligence, as the plan issued by the Gutenberg Summit in November 2017 for education and culture focused on three priorities for better use of artificial intelligence in teaching and learning represented in developing digital competencies and skills related to digital transformation; Education through data analysis and insight (Tuomi ,, 2018).

The academic efforts of researchers have also accelerated to explore the effects of artificial intelligence on education in general and higher education in particular, so the study (Khare, Stewart and Khare, 2018) emphasized the positive impact of artificial intelligence applications on student success, and the study (Tuomi, 2018) stressed the importance of artificial intelligence In providing rich educational environments and the possibilities of solving traditional problems of education using artificial intelligence applications, the study (Fryer, 2019) emphasized the role of robots in developing students 'interests in learning other languages. The study (Ma and Siau,2018) emphasized the importance of artificial intelligence in developing higher education and changing traditional methods of education.

In the opposite context, many studies reviewed the challenges arising from applications of artificial intelligence, especially with regard to the traditional functions of human resources, where a study (Fernández, Fernández, and Aburto, 2019) confirmed that the great challenge facing the University of the new millennium in the urgent need as a result of the development of information technology lies The need to plan, design, develop and implement digital skills in order to better train professionals who are able to understand the technological environment and develop it 
according to their needs. Some researchers (Harkut, and Kasat, 2019) also stressed the growing fears of the spread of artificial intelligence, and those fears were the lack of confidence: as it revolves around science, technology and algorithms that most individuals do not know, which makes it difficult for them to trust, and reduces the need for manpower This increases the chances of spreading unemployment.

In the Arab environment, the subject of artificial intelligence is still a relatively recent topic. Arab universities follow a traditional approach to education with the variation of these universities in infrastructure, so there are no applied research or studies or even theory on the topics of artificial intelligence, but research efforts were limited to shed light on the availability Education technology in these universities, although the future plans of these universities indicate the possibility of adopting artificial intelligence as one of the means that supports higher education.

In light of this, this study examines the extent of Arab universities' willingness to adopt artificial intelligence projects.

\section{Study Importance}

Theoretical importance: The study importance stems from my professional interest in academic education and my attempts to explore future academic situations.

Practical importance: This study seeks to determine the most probable scenario(s) of adopting AI in higher education and to provide them to the decision makers in higher education. This study is especially important for University leaders, namely the deans of affiliated colleges and the supporting deanships. It is also more relevant to distance learning deanships and continuing education as they need to be equipped with the most probable practices regarding $\mathrm{AI}$ applications and to be helped to become aware of and ready for the expected AI transformation in the education field.

\section{Study Problem}

Some researchers view artificial intelligence as a debatable subject and it is often represented in a negative way., Some may describe it as a convincing blessing for companies, while for some it is a technology that threatens the very existence of the human race because it may be able to control and control man, but in reality Artificial intelligence has affected our lifestyle either directly or indirectly and shaping tomorrow's future. This has prompted some researchers to ask an exciting question to what extent technology can revolutionize the world of education?. So this study examines the future of higher education if artificial intelligence is adopted and the extent to which Saudi universities are prepared to adopt applications of artificial intelligence in their educational systems.Study Questions

What is the recent situation of Academic Instruction in Higher Education in the light of AI transformations?

What is the most probable future scenario for Academic Instruction in Higher Education in the light of AI transformations?

What are the correct actions and measures that must be undertaken in higher education to make the most possible benefits of the AI transformations?

\section{Terms Definitions}

Higher Education: the researcher means, here, all the institutions that belong to the ministry of higher education including universities, colleges, and affiliated institutions.

Artificial Intelligence: A variety of methods, techniques, and tools for creating models and solving problems by simulating the behavior of perceived people.

Transformation: refers to the futuristic situation of the manners, styles, methods and approaches adopted by higher education. It also refers to the accompanied developments for AI transformations in teaching and learning curricula, in case higher education institutions decided to obtain the benefits of applications of artificial intelligence.

\section{Literature View}

Artificial intelligence is the simulation of human intelligence processes by machines, especially computer systems, and therefore it is a set of computational techniques inspired by the way humans use their nervous system and their body to feel, learn and act. (Harkut, and, Kasat, 2019).

Barrio (2018) explained the most obvious difference between human and artificial intelligence is that the computer (regardless of its capacity or energy) is limited to what it calls "signals" (logical programming language) with a higher memory capacity than human intelligence; however, unlike the latter, it is unable to interpret meanings. Therefore, the 
computer's operational or computational intelligence is limited to processing information, but it does not have the ability to understand what they are processing.

So artificial intelligence expresses science that is concerned with making smart machines that behave as one would expect humans to do, and artificial intelligence addresses the following areas:

- Natural Language Processing

- Robotics

- Speech Understanding

- Neural Network

- Expert stems

The primary aims of artificial intelligence is to enable machines to process information as closely as the human way of solving problems, Processing Parallel where several orders are executed at time runs out and this is the closest human way to solving problems. A better understanding of what human intelligence is by decoding the brain so that it can be simulated (Velik, 2012)

According to Chaudhary, 2017, artificial intelligence is beneficial for both students and teachers because it is used to create an educational environment and provide collaborative learning. The use of artificial intelligence and modern technologies can help teachers and students gain more educational experience, as well as provide information for teachers and management about the practices and scope of artificial intelligence in education required to gain excellence, according to (Fernández, Fernández, and Aburto, 2019)

The importance of artificial intelligence does not stop at this point but rather contributes to improving education for all different levels, while improving the qualitative process of education by providing students with feedback for their learning according to their requirements, and managing the integration of different forms of human interaction and information and communication technology.

Chaudhary, (2017) confirms that AI applications are beneficial for both students and teachers as it is used to create a learning environment and provide collaborative learning. Using computer intelligence and new technologies can help teachers and students gain more educational experience. It will provide information to teachers and management about the practices and scope of artificial intelligence in education required to gain excellence.

There are anticipations about life style in 2040, particularly in what concerns educational technology development whether in teaching methods, models and manners or learning approaches, techniques and patterns to make them easier than ever. However, there is a significant question: Are educational organizations and establishments ready for these exceptional unprecedented progressing technologies. One of these innovations is Artificial intelligence (AI) which is considered to be a part of computer science. It aims to design intelligent systems that give the same characteristics found in human behavior. It intentionally works on the principle of emulation of formations by which objects, events, and processes can be described using their qualitative properties and their logical and mathematical relationship (Otman \& Jameel, 2012 p.224).

Many researchers such as (Fernández, Fernández, and Aburto ,2019), (Mynbayeva et al., 2017) and Groff, 2013) attempted to research the general form of education after applying artificial intelligence and the summary of their ideas was the need to adopt effective and increasingly appropriate policies The capabilities of artificial intelligence are strengthened in a balanced way, according to the needs of the most representative institutions of society (such as universities), which requires a sharp change in the traditional educational laws as they fit with the applications of artificial intelligence

\section{How artificial intelligence affects higher education:}

Many researchers pointed out the effects of artificial intelligence on higher education, so it was confirmed (Ma, and, Keng, 2018) that artificial intelligence will affect higher education in two main areas

1- Curricula Artificial intelligence will have a major impact on the curricula in higher education, as the power of artificial intelligence contributes to providing elements of speed and accuracy, and this requires providing training opportunities for students to enhance their skills, and technical disciplines and liberal humanities may become more popular because these areas are less vulnerable. To invade artificial intelligence. " Areas like accounting and financial analysis that might be badly hit by artificial intelligence.

2- Enrollment: We may see a sharp drop in university enrollment due to the high cost, as higher education is not affordable for many because of that cost. 
Among the most important effects that higher education will experience according to (Fernández, Fernández, $\mathrm{L}$ and Aburto, 2019) is the replacement of the traditional language with the digital language. Digital language for students to deal with applications of artificial intelligence

\section{How (AI) systems will change the future of education?}

There are (10) rules for (AI) in education to probably change its future forever:

1- Artificial intelligence can automate basic activities in education, such as classification and grading.

2- AI systems can make educational programs tailor to the students' needs. That normally is made through current advanced technology applications and programs.

3- AI enables students to obtain an extra support. This feature works to empower the principles of educational establishments to serve students to the maximum extent.

4- Programs that depend on AI systems let students and teachers have the opportunity to provide useful comments for others to benefit and share experiences.

5- AI systems change the way to find information and interact with it. These types of intelligent systems play a big role in the way we interact with information in our personal and professional lives. Over the past few decades, AI systems have radically changed the manner we interact with information. With newer and more integrated technology, future students may have significantly different experiences in searching and finding facts than today's students.

6- AI systems indicate the areas that need improvement in the study courses, because this type of system helps to improve and fill gaps that can occur in educational courses. It helps to ensure that all students build the same conceptual foundations; instead of waiting for the teacher to listen, students get instant feedback that helps them understand the concept and remind them how to use it in the future.

7- AI systems can reduce the fear from learning by trial and error methods. AI systems can provide students with a way to learn in a relatively rule-free environment, especially when AI teachers can offer solutions for improvement. In fact, AI systems are the ideal form to support this type of learning because AI systems themselves often learn through the method of trial and error.

8- The data supported by AI systems can change the manner schools select their students.

9- AI systems can change the teachers' role. That was really expected with technology advancement, particularly with the emergence of the smart devices.

10- AI systems will change the students' learning location, who teach them, as well as the style of gaining basic skills. AI systems allow students and teachers to grasp the opportunity to choose the proper places for learning and enhance their educational abilities whether at home, school or other places such as Starbucks and the like (McArthur, Lewis \& Bishary, 2005).

\section{Examples for the Application of AI in the Classroom Today:}

Tutoring: by the time AI systems are applied in academic lecture halls, classrooms, laboratories and interactive study places in colleges, institutes or other educational institutions, there will be no need for the teacher to repeat the explanation of a certain topic or a part of it and spend more time with students to understand that part; the student can now achieve that easily with AI without embarrassment or waste of time.

Using AI in Students' Grading: instructors suffered because of the time wasted in the grading process adopted for a long time in traditional exams, computer tests and others. With AI, the situation is going to be different: teachers can quit grading to spend more time with students.

Improving Administrative Tasks: This has been clear at universities and most of educational organizations around the world by virtue of AI applications.

Global Classroom Possibility: AI systems supplied with instant translations and subtitles will empower new generation students to go beyond all the world broads. AI will eliminate the classrooms' walls to allow students to share knowledge and participate in different learning global environments (Boulay, 2016).

\section{Previous Studies}

There are many previous literature that discussed the topic of artificial intelligence and its impact on higher education, and among these studies, The Fernández,, Fernández, L and Aburto, (2019) study reviewed the impact of artificial intelligence on higher education and the study concluded that the coming period will witness the transition 
from the traditional roles of universities to new ones such as replacing the traditional language with the digital language, and the development of teaching methods in a new way which It requires enhancing students' skills to adapt to social intelligence applications.

(Ma and, Keng (, 2018)) study revealed the impact of artificial intelligence on higher education, as these effects were represented by a low dependence on human resources in education, and new skill sets will be needed. Higher education needs the challenge of preparing students for the AI revolution and providing students with the skill sets necessary to compete in the era of artificial intelligence. This recent research aims to shed light on the development of higher education and the revolution with the advancement of artificial intelligence?

Khare, Stewart and Canada, ( 2018) study attempted to reveal the potential of artificial intelligence to positively influence a student's success, the study reviewed the form of education when applying artificial intelligence as students will rely more on administrative staff while faculty members at the Institute of Higher Education oversee management systems Learning. The study concluded that the applications of artificial intelligence will increase the ability of educational institutions to perform their primary task of teaching, learning and research

Gamoura et al. (2018) study tried to prove that the technical reality as well as the moral and technological barriers prevent suggest the idea of absolute machine freedom in decision-making in the near future, including fears currently mounting on the media and academia, despite the characteristics of AI including automatic actions, self-development and automatic machine learning. The researchers gave the foundations of artificial intelligence and its characteristics and some of its living models to shed light on the reality of its developments and aspirations between what it actually reached and what it hopes to reach.

Abu Hasanein (2018) in his dissertation entitled “An Intelligent Tutoring System for Developing Education: Case Study (Israa University)" mentioned that a smart tutor was designed using an intelligent tutoring system (ITS) tool improved by Prof. Sami Abu Nasser to develop the process of teaching the computer skills course. This workshop is a university training course that teaches students of Israa University on different samples of students. After the completion of the course and the evaluation of the lecturers who taught the course and used the system in their teaching process, a set of conclusions and recommendations have been reached. The tutor's use of the Artificial Intelligence tools is important in the development of laboratory teaching and it has positive results in improving the level of scientific department students.

In a study entitled "Educational Applications of Artificial Intelligence in Social Studies," Al-Saud (2016) aimed to uncover the role of $\mathrm{AI}$ in the development of teaching strategies and models, with concentration on its applications in academic learning and teaching in Social Studies department. The study concluded with a definition of AI, a distinction between AI and human intelligence, and suggestions to conduct more AI-related studies in the Social Studies field.

Alqattan (2012) conducted a study entitled "The Readiness of Managerial Leaderships to adopt the Applications of Artificial Intelligence in Educational Organizations" where he tried to fathom the managerial leaders' ability to activate the requirements needed for applying $\mathrm{AI}$ in their educational organizations. The results show that there is an effective interest towards adopting artificial intelligence in the managerial leadership of the organizations participating in the study.

Like the afore-mentioned studies, the present study subscribes itself in the same research field (AI in education). However, this research is distinct thanks to its method as a futuristic study and its concentration on the potential scenarios as determined by experts' expectations about the future of higher education and AI transformation.

\section{Mythology}

The qualitative research methodology was used to identify the future of higher education in the light of artificial intelligence from the viewpoint of academic experts in the Kingdom of Saudi Arabia.

\subsection{Study Population and Sample}

This study population consists of faculty members at Prince Sattam bin Abdulaziz university. They are PhD holders. They belong to all professorship grades. According to the university statistics center, their number is (875). The researcher chose sample of academic (30) by using (Delphi) style,

The tool of the study was an open question posed to the study sample, to solve the future of higher education in light of the applications of artificial intelligence. 


\section{Statistical Analysis}

The researcher collected opinions from the participating experts' perspectives and their feedback. Their points of view and answers on the open-end questions and their choosing from some multiple-choices clauses which enabled the researcher to finally draw the direction of futuristic scenario for higher education on the light of AI transformations. There are three rounds have been done during separate periods, through each once the researcher was reviewing all their responses then selected mutual feedbacks, and modified or omitted other answers that have disputes then repeated that again in order to have an agreed scenario.

\section{The Results of Study}

The experts' final feedback regarding the current situation of Academic Instruction in Higher Education in the light of AI transformations tend to confirm that there is total satisfaction about what technology has achieved and that there is a belief in technology capacities. Besides, the points of view of the majority of the faculty community reveal that there is a trust in technological progress.

The experts' final view regarding the second question in this study makes it clear that the most possible future scenario in Academic Instruction in Higher Education on the light of AI transformations is the optimistic scenario. The experts pointed out that the AI tools can actively participate in many academic aspects namely, improving academic education and students' learning, promoting academic guidance, enhancing student assessment and scoring process, activating the university and student activities, improving programs and quality assurance, providing virtual reality learning (VR), providing additional support for students, and making trial and error learning less frustrating.

As far as the correct actions that must be undertaken in higher education to gain the most possible benefits of AI transformations, the experts recommend to prepare the faculty members to be ready to utilize AI products effectively through training-courses, workshops, seminars, and internships.

\section{Conclusion}

There is a gap between the previous theoretical literature and studies -which some of them are mentioned in this study- from side, and what this research uncovered from other side, that gap regards to the absence of depth awareness about practical usages to get effectively benefits of the smart tools that will be available in the very near future in higher education field, the advanced smart productions definitely will be transferred to the universities of the rich Gulf states such as Saudi Arabi and will be accompanied with user's knowledge and his will, but unfortunately without a real cognitive preparation and without a true conscious perception of the multiple and various great roles of Artificial Intelligence and it's advantage or disadvantage in academic processes, whether administrative procedures or teaching and learning styles. Therefore, the researcher provides the next suggestions and recommendations for his university and to whom may be interested in to treat this issue and concentrate on effective solutions in order to achieve the targets of this study.

\section{Recommendations and suggestions}

The researcher recommends universities' leaders to do these following steps:

-Increasing awareness among specialists of the requirements of applying artificial intelligence in education

-Attention to the challenges arising from the applications of artificial intelligence to the jobs and roles of academics in universities

- Organize academic conferences on all AI issues.

- Create community cooperation with specialized companies in AI field. Finally, the researcher encourages academic researchers to conduct more studies about the future of all levels of education in the light of AI transformations.

\section{References}

Alnajjar, Mohammed. (2012). The Effectiveness of a Program Based on Artificial Intelligence Technology in The Development the Skills of Educational Websites Creating for The Students of The Information Technology Department in The Light of Total Quality Standards. Unpublished Master Thesis. Cairo University. Egypt.

Alqattan, Basmah. (2012). The Readiness of Managerial Leaderships to adopt the Applications of Artificial Intelligence in Educational Organizations. Buhuth Mustaqbaliya Scientific Periodical Journal, 3, 67-88.

Al-Saud, Sarah. (2017). Educational Applications of Artificial Intelligence in Social Studies. Soulouk Journal, 3, 133-163. No. 3. 
Boulay, Benedict. (2016). Artificial Intelligence as an Effective Classroom Assistant. IEEE Intelligent Systems, 31(6), Nov.-Dec. 2016.

Chaudhary, S (2017). Artificial Intelligence in Education. International Journal of Social Science \& Interdisciplinary Research, 6(4), APRIL (2017), 16-28

Fryer, L. K, Nakao, K \& Thompson, A (2019). Chatbot learning partners: connecting learning experiences, interests and competence. Computers in human behaviors, (93), 279- 289.

Gamoura, Samiah, Mohamed, Bay \& Krosh, Haiziah. (2018). Artificial Intelligence: A New Challenge of Law. International Forum. Algeria (26-27 November 2018)

Groff, J. (2013). Technology-rich innovative learning environments. OCED CERI Innovative Learning Environment project, 2013, 1-30.

Harkut,D \& Kasat, K (2019). Artificial Intelligence - Challenges and Applications, Submitted: November 30th 2018Reviewed: January 22nd 2019Published: March 19th 2019

John McCarthy (2007-11-12). Applications of AI" ،www.formal.stanford.edu, Retrieved 2018-8-11. Edited.

Khare, K., Stewart, B. \& Khare, A. (2018). Artificial intelligence and the student experience: An institutional perspective. The International Academic Forum (IAFOR).

Ma, Yizhi \& Siau, Keng L. (2018). Artificial Intelligence Impacts on Higher Education. MWAIS 2018 Proceedings. 42. Proceedings of the Thirteenth Midwest Association for Information Systems Conference, Saint Louis, Missouri May 17-18, 2018

Mariño, S. \& Primorac, C. (2016). Propuesta metodológica para desarrollo de modelos de redes neuronales artificiales supervisadas. International Journal of Educational Research and Innovation, 6, 231-245.

McArthur, D., Lewis, M. \& Bishary, M. (2005). The Roles of Artificial Intelligence in Education: Current Progress and Future Prospects. Journal of Educational Technology, 1(4), 42-80. Retrieved October 31, 2019 from https://www.learntechlib.org/p/161310/.

Morín, E. (2018). De la reforma universitaria. Recuperado de: http://beu.extension.unicen.edu.ar/xmlui/handle/123456789/275

Mynbayeva A,, advakassova, Z \& Akshalova, B. (2017). Pedagogy of the Twenty-First Century: Innovative Teaching Methods. Published: December 20th 2017

Ocaña-Fernández, Y., Valenzuela-Fernández, L. A. \& Garro-Aburto, L. L. (2019). Artificial Intelligence and Its Implications in Higher Education. Journal of Educational Psychology-Propositos y Representaciones, 7(2), 553-568.

Osman, Hussein Osman, Jamil \& Ahmed Adel. (2012). The possibility of using artificial intelligence techniques to control the quality of internal audit. 11th Annual Scientific Conference. al zaytona University.

Tuomi, I. (2018). The impact of artificial intelligence on learning, teaching, and education. Policies for the future, available at: http://publications. jrc. ec. eu/repository/bitstream/JRC113226/jrc113226_jrcb4_the_impact_of_artificial_intelligence_on_learning_final_ 2. pdf.

Velik, R (2012). AI Reloaded: Objectives, Potentials \& Challenges of the Novel Field of Brain-Like Artificial Intelligence. BRAIN. Broad Research in Artificial Intelligence and Neuroscience, 3(3). 25-54. 